\title{
STRUCTURAL AND MECHANICAL PROPERTIES OF DIAMOND-LIKE CARBON FILMS PREPARED BY PULSED LASER DEPOSITION WITH VARYING LASER INTENSITY
}

\author{
M. Bonelli ${ }^{1}$, A. C. Ferrari ${ }^{2}$, A. P. Fioravanti ${ }^{3}$, A. Miotello ${ }^{1}$, P. M. Ossi 4 \\ ${ }^{1}$ Istituto Nazionale per la Fisica della Materia (INFM) and Dipartimento di Fisica, Università \\ di Trento, I-38050 Povo (TN), Italy \\ 2 Department of Engineering, Cambridge University, Cambridge, UK \\ 3 Dipartimento di Ingegneria Nucleare, Politecnico di Milano, I-20133 Milano, Italy \\ 4 Istituto Nazionale per la Fisica della Materia (INFM) and Dipartimento di Ingegneria \\ Nucleare, Politecnico di Milano, I-20133 Milano, Italy
}

\begin{abstract}
Diamond-like carbon (DLC) films have been prepared by pulsed laser deposition (PLD) (wavelength $248 \mathrm{~nm}$ ), ablating highly oriented pyrolytic graphite (HOPG) at room temperature in a vacuum of $10^{-2} \mathrm{~Pa}$, at fluences between 0.5 and $35 \mathrm{Jcm}^{-2}$. Films have been deposited on $\mathrm{Si}(100)$ with and without a $\mathrm{SiC}$ interlayer. Structural analysis, such as visible and UV Raman, Infrared and Electron Energy Loss (EEL) spectroscopies show that the films are hydrogen-free and undergo a transition, from mainly disordered graphitic to up to $80 \%$ tetrahedral amorphous carbon (ta-C), above a laser threshold fluence of $5 \mathrm{~J} \mathrm{~cm}^{-2}$. The measured residual stresses of as deposited ta-C films do not exceed $2 \mathrm{GPa}$. Scratch tests show excellent adhesion properties. Low friction coefficients $(0.05-0.1)$ have been measured in ambient humidity. Nanoindentation indicates that film hardness is as high as $70 \mathrm{GPa}$.
\end{abstract}

\section{INTRODUCTION}

Growing interest has been devoted to Pulsed Laser Deposition (PLD) of diamond-like carbon (DLC) films with a high content of tetrahedrally coordinated atoms [1]. With respect to mechanical applications, the main limitation of the films are limited thicknesses and often problematic film-substrate adhesion due to high compressive stresses. We prepared DLC films by PLD and characterized them both structurally and mechanically.

\section{EXPERIMENTAL PROCEDURES}

The films were deposited in a vacuum chamber with a base pressure of $10^{-3} \mathrm{~Pa}$, and operating at a pressure of $10^{-2} \mathrm{~Pa}$. Highly oriented pyrolitic graphite (HOPG, purity, 99.99\%), was ablated with laser pulses from a Lambda Physik LPX220I Excimer Laser (wavelength $\lambda=248 \mathrm{~nm}$, pulse duration $\tau=20 \mathrm{~ns}$, repetition frequency $10 \mathrm{~Hz}$, incidence angle $45^{\circ}$ ), changing the fluence between $0.5 \mathrm{Jcm}^{-2}$ and $35 \mathrm{Jcm}^{-2}$. Different types of ultrasonically cleaned substrates were used, as shown in Table I. We chose $\mathrm{Si}(100)$ for structural analyses and $\mathrm{Si}(100)$ coated with sputter deposited $\mathrm{SiC}$ to reduce substrate effects in nanoindentation. Film and substrate thicknesses, as determined with a DEKTAK IIA profilometer, are reported in Table I together with the laser fluences. Usually deposition rates were of the order of 0.6 $\mathrm{nms}^{-1}$ at our repetition frequency.

Unpolarised visible Raman spectra were recorded in backscattering geometry for $514.5 \mathrm{~nm}$ excitation from an Ar ion laser using a Jobin-Yvon T64000 triple grating spectrometer. UV 
Raman spectra were collected on an UV-enhanced CCD camera on a Renishaw micro-Raman System 1000 spectrometer, modified for use at $244 \mathrm{~nm}$, with fused silica optics throughout. FTIR spectra were taken at room temperature, in dry air, using a Win Rad Fast Trasform spectroscope over the $400-4000 \mathrm{~cm}^{-1}$ range. EELS measurements were carried out on a dedicated VG501 scanning transmission electron microscope fitted with a spectrometer with a McMullan parallel EELS detection system [2]. The residual internal stresses of the films deposited on Si were determined by Stoney's equation, measuring film curvature by a UBM Messtechnik Laser Microfocus profilometer. Film hardness was determined by a Nano Instruments (type II) ultra low load depth-sensing nanoindenter (ind. Depth $\sim 50 \mathrm{~nm}$ ), analyzing data by the Oliver-Pharr procedure [3]. Film-substrate adhesion was tested by scratch tests, performed with a CSEM Revetest Automatic Scratch-Tester equipped with a Rockwell shaped diamond indenter (conical angle $120^{\circ}$, hemispherical tip of $100 \mu \mathrm{m}$ radius), at a scratching speed of $10 \mathrm{~mm} \mathrm{~min}^{-1}$ and a loading rate of $10 \mathrm{~N} \mathrm{~mm}^{-1}$.

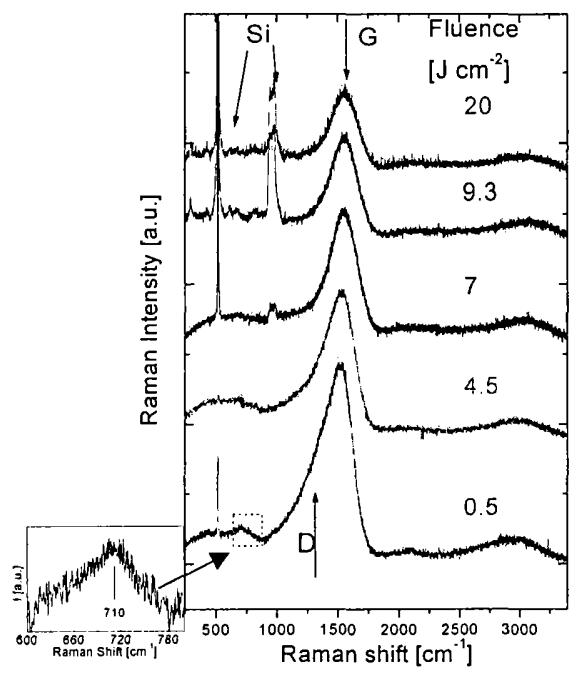

Fig. 1 Visible Raman spectra of DLC films grown by PLD at increasing laser fluences. The inset shows a magnification of the band centered around $710 \mathrm{~cm}^{-1}$ in a film deposited below $\mathrm{f}_{\mathrm{t}}$.

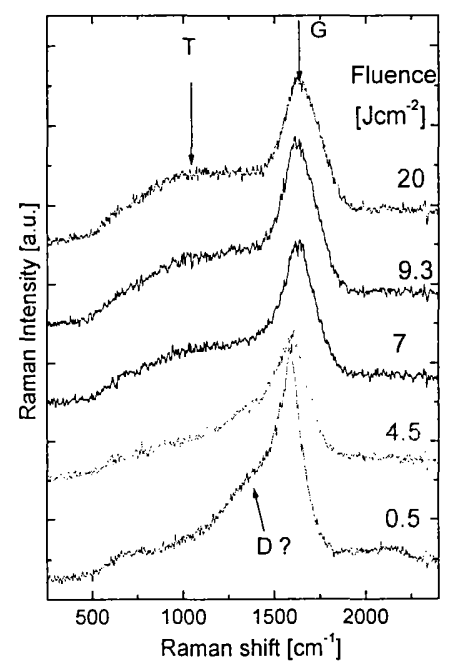

Fig 2. UV Raman spectra of DLC films grown by PLD at increasing laser fluences

\section{RESULTS AND DISCUSSION}

In Fig.1-2 the Visible and UV Raman spectra are reported for films grown at different fluences. Visible Raman spectra show two main features, the $D$ peak $\left(\sim 1350 \mathrm{~cm}^{-1}\right)$, due to breathing modes of rings, and the $G$ peak $\left(\sim 1560 \mathrm{~cm}^{-1}\right)$ due to the relative motion of $\mathrm{sp}^{2}$ carbon atoms [4-6]. The UV Raman spectra consist of a G peak at $\sim 1660 \mathrm{~cm}^{-1}$ and a T peak at $\sim 1100 \mathrm{~cm}^{-1}$, attributed to all $\mathrm{sp}^{3} \mathrm{C}-\mathrm{C}$ bond vibrations[7]. However, for low laser fluences, 
another peak at $\sim 1400-1430 \mathrm{~cm}^{-1}$ becomes evident. This peak has not been reported before and we could consider it as the correspondent of the $\mathrm{D}$ peak. Further work will be devoted to study its nature. Visible Raman spectra, were fitted with a combination of a Breit-Wigner Fano for the G peak, and a lorentzian for the D. UV Raman spectra were fitted with 2 lorentzians, for the $\mathrm{G}$ and $\mathrm{T}$ peak, and, at low fluences, with another lorentzian for the extra peak. Fig 3-4 show the evolution of Raman parameters with increasing laser fluence. Note that the maximum of the BWF is reported, rather than it's centre, to allow comparison with literature data using symmetric lineshape fitting [6].

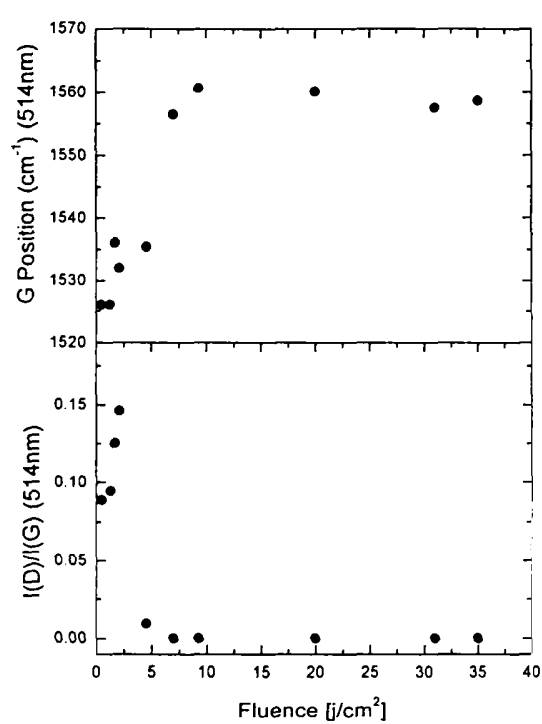

Fig 3. $I(D) / /(G)$ and $G$ Position in function of fluence for $514 \mathrm{~nm}$ excitation

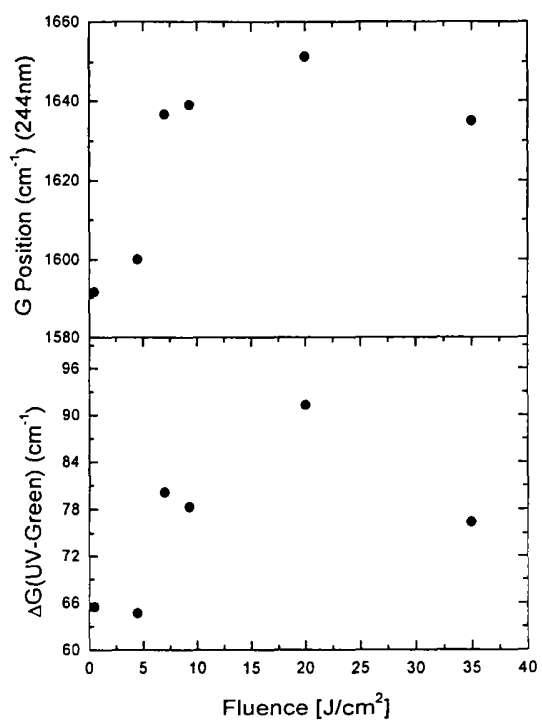

Fig 4. G position for UV excitation and difference in $\mathrm{G}$ position for $\mathrm{UV}$ and green excitation, $\Delta \mathrm{G}$

Data in Fig 3 indicate that above a threshold fluence $\left(f_{t}\right)$ value of $5 \mathrm{Jcm}^{-2}$ the films consist largely of amorphous tetrahedrally bonded carbon $(t a-C)[4,6]$. Indeed, $I(D) /(G) \sim 0$ in combination with an high $\mathrm{G}$ peak position is a sufficient condition to confirm the high $\mathrm{sp}^{3}$ in the films $[4,6]$. Moreover, the intensity of the $T$ peak relative to the $G$ peak is maximum in UV Raman for $\mathrm{f}>\mathrm{f}_{\mathrm{t}}$, indicating high $\mathrm{sp}^{3}$ fraction [7]. G peak position in UV-Raman is blue shifted with respect to $G$ peak in green Raman due to the resonant selection of wider band gap $\pi$ states, from $\mathrm{sp}^{2}$ groups with higher vibrational frequency [6, 7]. Fig 4 shows that $\Delta \mathrm{G}\left(\mathrm{UV}\right.$-green) is max for $20 \mathrm{~J} / \mathrm{cm}^{-2}$, consistent with shortest $\mathrm{sp}^{2}$ chains and highest $\mathrm{sp}^{3}$ fraction. $\Delta G$ (UV-green) is minimum for $f<f_{t}$, thus indicating clustering of the $\mathrm{sp}^{2}$ phase and lower $\mathrm{sp}^{3}$ content. A deeper discussion of the trends in visible and UV Raman will be presented elsewhere. The magnification of the low frequency Raman spectrum of a film deposited at $0.5 \mathrm{Jcm}^{-2}$ (inset of Figure 1) shows a broad band centered on $710 \mathrm{~cm}^{-1}$. Such a feature, which is absent in films deposited at high fluences, could be attributed to a collective in-plane deformation of graphitic islands, which results in a peak in the vibrational density of states [5]. Typical FTIR transmission spectra of representative films deposited on Si are reported in Figure 5. Two bands are evident in the spectra of films deposited at fluences 
below $\mathrm{f}_{\mathrm{t}}$ : the first, around $710 \mathrm{~cm}^{-1}$, is attributable to the graphite vibrational mode observed also in Raman spectra [5], while the second, around $1250 \mathrm{~cm}^{-1}$, was attributed to the stretch of mixed $\mathrm{sp}^{2}-\mathrm{sp}^{3} \mathrm{C}-\mathrm{C}$ bond [8].

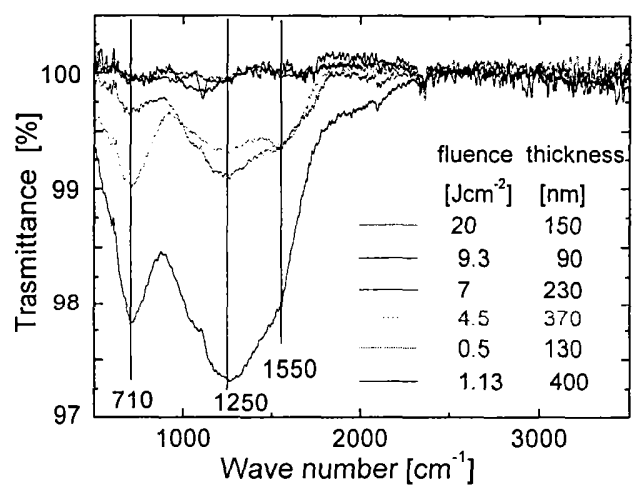

Fig 5. FTIR transmission spectra. From the top to the bottom Fluence is, $20,9.3,7,4.5,0.5,1.13 \mathrm{~J} / \mathrm{cm}^{-2}$

The shoulder at about $1550 \mathrm{~cm}^{-1}$ is due to the vibrations of the $\mathrm{sp}^{2} \mathrm{C}=\mathrm{C}$ bonds [8]. No evidence of the above bands is present in the spectra of the films deposited above $f_{t}$, which are transparent, confirming that, for increasing fluence, a structural transition from graphitic carbon to ta-C occurred. In all spectra, the lack of absorption bands around $2800-3100 \mathrm{~cm}^{-1}$, attributed to the $\mathrm{C}-\mathrm{H}_{x}$ stretching modes, indicates that our films are hydrogen free $(\mathrm{H}$ content is lower than the detectable limit of 0.5 at.\%) [8].

The $\mathrm{sp}^{3}$ fraction in the film deposited at $0.5 \mathrm{~J} / \mathrm{cm}^{-2}$, as measured by EELS, is around $40 \%$ while in the films deposited at $20 \mathrm{Jcm}^{-1}$ it is $80 \%$. For the same samples X-ray reflectivity measurements gave bulk densities of $2-2.2 \mathrm{~g} / \mathrm{cm}^{-2}$ and $2.9-3 \mathrm{~g} / \mathrm{cm}^{-2}$, with the presence of layers [9]. Referring to Table $\mathrm{I}$, all films deposited at fluences below $\mathrm{f}_{\mathrm{t}}$ show a low content (not lower than about 40\%) of fourfold coordinated carbon, while in films deposited at fluences above $\mathrm{f}_{\mathrm{t}} \mathrm{sp}^{3}$ content is progressively increasing up to $80 \%$.

Film stresses are compressive and increase with fluence, still being not higher than $2 \mathrm{Gpa}$. This value is the lowest reported to date for an as-deposited ta-C film, with no $\mathrm{B}, \mathrm{Si}$ introduction or post deposition annealing. In fact the usual range of internal stresses in as deposited ta-C films is of the order of $10 \mathrm{Gpa}$, or more [10,2].

In films deposited on $\mathrm{Si}$, the upper critical load LC2 (at this load the film is completely removed from the scratch path) increases with both laser fluence and film thickness. As a rule, films deposited above $f_{t}$, with thickness not shallower than $100 \mathrm{~nm}$, show LC2 between 16 and $20 \mathrm{~N}$, corresponding to maximum Hertzian contact pressures $\mathrm{p}_{\max }$ around $16 \mathrm{Gpa}$. These values for LC2 and $\mathrm{p}_{\max }$ are considerably higher than those reported for single layer DLC films $500 \mathrm{~nm}$ thick, deposited on 440 steel (LC2 $\left.\sim 10 \mathrm{~N}, \mathrm{p}_{\max } \sim 1 \mathrm{Gpa}\right)[11,12]$. In films deposited on $\mathrm{Si}+\mathrm{SiC}, \mathrm{LC} 2$ values are around $15 \mathrm{~N}$. This does not mean that DLC films deposited on $\mathrm{SiC}$ show adhesion and load supporting capacity worse than those of films deposited on $\mathrm{Si}$, since harder substrates sink-in less under the indenter, so that stress and strain distributions in the film and at the interface are modified. Scanning Electron 
Microscopy (SEM) images of scratches corresponding to LC2s indicate that scratch diameters are larger in films deposited on $\mathrm{Si}$ than on $\mathrm{Si}+\mathrm{SiC}$; notwithstanding the different $\mathrm{LC} 2$ values, $\mathrm{p}_{\max }$ is comparable in the two films. Friction coefficients, as deduced from scratch tests in ambient humidity, are lower than 0.08 , with minimum values of about 0.05 (see Table I). Scratch tests indicate that ta-C adhesion to $\mathrm{Si}+\mathrm{SiC}$ is better than to $\mathrm{Si}$. Due to the relevant thickness changes between films deposited on Si respectively at low and high fluences (see Table I), it was not possible to identify a fluence value marking a sharp transition in film mechanical properties, although they are improved in films deposited at higher fluences. In films deposited on $\mathrm{Si}$, hardness increases with fluence up to values of $40 \mathrm{Gpa}$. As the harder films are not thicker than $130 \mathrm{~nm}$ and the indentation depth is $50 \mathrm{~nm}$, film hardness is certainly underestimated due to the influence of the comparatively soft substrate. Indeed in ta-C films deposited on $\mathrm{Si}+\mathrm{SiC}$ at the same fluences as those deposited on $\mathrm{Si}$, hardness is as high as $70 \mathrm{Gpa}$, which is more reliable due to the reduction in substrate effects (see Table I).

\begin{tabular}{|c|c|c|c|c|c|c|c|}
\hline $\begin{array}{c}\text { Fluence } \\
{\left[\mathbf{J}_{\mathbf{c}} \mathbf{c m}^{2}\right]}\end{array}$ & Substrate & $\begin{array}{c}\text { Thickness } \\
{[\mathbf{n m}]}\end{array}$ & $\begin{array}{c}\mathbf{s p}^{3} \\
{[\%]}\end{array}$ & $\begin{array}{c}\text { Internal stress } \\
{[\mathbf{G P a}]}\end{array}$ & $\begin{array}{c}\text { LC2 } \\
{[\mathbf{N}]}\end{array}$ & $\begin{array}{c}\text { Friction } \\
\text { coefficient }\end{array}$ & $\begin{array}{c}\text { Hardness } \\
{[\mathbf{G P a}]}\end{array}$ \\
\hline 0.5 & $\mathrm{Si}(100)$ & 120 & 42 & 0 & 8 & 0.07 & 27 \\
1.13 & $\mathrm{Si}(100)$ & 400 & low & 0.30 & 20 & 0.065 & - \\
4.5 & $\mathrm{Si}(100)$ & 370 & - & 0.92 & 17 & 0.06 & - \\
7 & $\mathrm{Si}(100)$ & 230 & high & 1.6 & 18.5 & 0.077 & - \\
9.3 & $\mathrm{Si}(100)$ & 90 & high & & 14 & 0.053 & - \\
20 & $\mathrm{Si}(100)$ & 130 & 80 & 1.7 & 18.5 & 0.07 & 36 \\
29 & $\mathrm{Si}(100)+$ & 210 & high & & 14 & $0.11^{(*)}$ & 70 \\
\hline
\end{tabular}

(*) Surface roughness about $10 \mathrm{~nm}$.

Table I Collection of relevant data on deposition parameters, structural and mechanical properties of DLC films.

\section{CONCLUSION}

We deposited PLD ta-C films 100-200 nm thick on Si both with and without a SiC interlayer, working in a vacuum of $10^{-2} \mathrm{~Pa}$. Structural characterizations showed that above a threshold fluence of $5 \mathrm{Jcm}^{-2}$ the films largely consist of ta-C, with low stress ( $\left.<2 \mathrm{Gpa}\right)$, up to $80 \% \mathrm{sp}^{3}$ and hardness of $70 \mathrm{Gpa}$. The better adhesion properties are shown by ta-C on $\mathrm{SiC}$.

\section{ACKNOWLEDGEMENTS}

The authors are grateful to Prof. G. Caglioti and C. E. Bottani, Dipartimento di Ingegneria Nucleare, Politecnico di Milano, for discussions on the mechanical properties of DLC films and Raman spectroscopy, and to T. Sasaki, Joint Research Center, Ispra, for nanoindentation measurements, Prof D. Bathcelder of Leeds University for UV Raman facilities, V. Stolojan of Cavendish Laboratory, for EELS measurements, A. LiBassi, of Durham University, for XRR measurements. Financial support by CNR-Progetto Finalizzato Materiali Speciali per 
Tecnologie Avanzate II is acknowledged. A.F.C. acknowledges funding by an E.U. TMR Marie Curie research fellowship. P. M. O. acknowledges partial funding by INFM Advanced Research Project CLASS.

\section{REFERENCES}

[1] T. A. Friedmann, J. P. Sullivan, J. A. Knapp, D. R. Tallant, D. M. Follstaedt, D. L. Medlin and P. B. Mirkarimi, Appl. Phys. Lett. 71, 3820 (1997)

[2] P. J. Fallon, V. S. Veerasamy, C. A. Davis, J. Robertson, G. A. J. Amaratunga and W. I. Milne, Phys. Rev. B, 484777 (1993)

[3] G. M. Pharr and W. C. Oliver, MRS Bulletin 7, 1564 (1992).

[4] S. Prawer, K. W. Nugent, Y. Lifshitz, G. D. Lempert, E. Grossman, J. Kulik, I. Avigal and R. Kalish, Diamond Rel. Mat. 5, 433 (1996).

[5] C. Mapelli, C. Castiglioni, E. Meroni and G. Zerbi, K. Mullen, Phys. Rev. B, 6012710 (1999).

[6] A. C. Ferrari, J. Roberston, Phys. Rev. B, submitted.

[7] K. W. R. Gilkes, H. S. Sands, D.N. Batchelder, J. Robertson, W.I. Milne, Appl. Phys. Lett., 701980 (1997)

[8] B. Dishler, Amorphous Hydrogenated Carbon Films, EMRS Symp proc. Vol 17, ed. P. Koidl and P. Oelhafen (Les Editions de Physique, Paris, 1987)

[9] A. Li Bassi, A. C. Ferrari, V. Stolojan, B. K. Tanner, J. Robertson, L. M. Brown, Diamond Relat. Mater., to be published (1999).

[10] X. Shi, D. Flynn, B. K. Tay, S. Prawer, K. W. Nugent, S. R. P. Silva, Y. Lifshitz and W. I. Milne, Phil. Mag. B 76, 351 (1997).

[11] A. A. Voevodin, M. S. Donley and J. S. Zabinski, Surf. Coat. Technol. 92, 42 (1997).

[12] A. A. Voevodin, M. S. Donley, J. S. Zabinski and J. E. Bultman, Surf. Coat. Technol. 76-77, 534 (1995). 